\title{
Low-temperature plasma applications in chemical fungicide treatment reduction
}

\author{
Lucia Hoppanováa, Veronika Medveckáb, Juliana Dylíkováa, Daniela Hudecováa, \\ Barbora Kaliňákováa, Svetlana Kryštofováa , Anna Zahoranováb \\ ${ }^{a}$ Institute of Biochemistry and Microbiology, Faculty of Chemical and Food Technology, Slovak University of Technol- \\ ogy, Radlinského 9, 81237 Bratislava, Slovak Republic \\ ${ }^{b}$ Department of Experimental Physics, Faculty of Mathematics, Physics and Informatics, Comenius University, \\ Mlynská dolina F2, 84248 Bratislava, Slovak Republic \\ lucka.hopp@gmail.com
}

\begin{abstract}
In order to reduce the environmental burden of chemicals, various new alternatives to seed protection are being sought. Our aim was to find an environmentally acceptable solution leading to the inactivation of seed-borne phytopathogenic fungi Fusarium culmorum on the surface of wheat and barley seeds with a positive effect on their germination. As a low-temperature plasma (LTP) source, a Diffuse Coplanar Surface Barrier Discharge (DCSBD) was used. Plasma generated by DCSBD is non-equilibrium, cold, diffuse, macroscopically homogeneous even in ambient air at atmospheric pressure. Experimental results showed that LTP treatment in the range of 120-300 s significantly inhibits the growth of F. culmorum on the surface of the seeds. The efficiency of LTP treatment was compared with traditional seed protection processes using chemical fungicide and also with combined seed pretreatment by plasma and subsequent application of chemical fungicide. No growth of F. culmorum was observed after the combination of Vitavax 2000 fungicide application in the dose of $10 \%$ and $60 \mathrm{~s}$ of LTP treatment even on the 5 th day of incubation. Better wettability of seeds with the chemical fungicide was related to the change on seed surface, which becomes hydrophilic after $10 \mathrm{~s}$ of LTP application. Short LTP exposure times did not affect germination and improved the growth parameter of cereal seeds. By combining physical (LTP) and chemical (Vitavax 2000) treatments of cereal seeds, it is possible to effectively reduce the required amount of chemical fungicide and to stimulate germination and early growth seed parameters.
\end{abstract}

Keywords: Cereal seeds; Chemical fungicide Vitavax 2000; Decontamination; Fusarium culmorum; Germination; Low-temperature plasma

\section{Introduction}

Cereals represent the main part of human and animal nutrition. Wheat, barley and maize are grown on more land area than any other food crop. In 2017, European production of wheat was 270 million tons, making it the second most-produced cereal after maize. European production of barley was 89 million tons (FAOSTAT, 2019). Cereal contamination by microscopic fungi is one of the main causes of stored seeds depletion since microscopic mycelial fungi reduce seed germination and seed nutritional quality (Ramos et al., 1998). Cereals are particularly susceptible to microbial deterioration during growth, ripening, storage and processing. Mycotic contamination of cereals is the highest at the time of harvest when it can reach $10^{6} \mathrm{CFU}$ (Colony Forming Units) of microscopic fungi in one gram of seed (Tančínová et al., 2001).

Microscopic mycelial fungi can grow on cereal surface in form of mycelium and spores (Laca et al., 2006). Genera Alternaria, Fusarium and Cladosporium are primarily responsible for the contamination of cereal seeds in the field (Montville and Matthews, 2005). Stored seeds are contaminated mainly by
Penicillium and Aspergillus species (Magan et al., 2003). The development of fungal contamination is affected by storage conditions such as temperature, relative humidity, $\mathrm{pH}$, and aqueous activity. During optimal storage conditions, the number of CFU of fungi decreases (Tančínová et al., 2001). The greatest risk for food safety and quality at pre- and post-harvest stages is associated with the production of mycotoxins, which are species and strain specific (Montville and Matthews, 2005). Fusarium spp. (a model organism in this study) are well-known pathogens of cereals that produce mycotoxins, e.g. trichothecenes, fumonisins, zearalenone, deoxynivalenol, with carcinogenic, mutagenic and genotoxic effects. They cause acute or chronic human and animal health problems (Pereira et al., 2014). This fungal genus causes a crop disease - fusariose, which reduces germination and seed quality and causes crop losses (McMullen et al., 2012).

For more than 200 years, fungicides have been used to protect plants from fungal infections in order to increase crop yield and reduce economic losses. There are currently around 150 different fungicidal compounds used in global agriculture (Ishii and Holloman, 2015; Lucas et al., 2015). Protection 
of seeds by chemical agents leads to contamination of the environment and accumulation of hazardous chemicals in soil and water. However, excessive use of chemicals is now being abandoned and new alternatives for crop protection with minimal environmental impact are implemented.

In recent years, the research and application of lowtemperature plasma (LTP) has received great attention. Plasma finds its application in various spheres of interest in biological sciences (Šimončicová et al., 2019). A lot of significant data were obtained by the application of plasma treatment to plant seeds, indicating positive effects on seed germination, quality of plants grown from the plasma treated seeds, early growth parameters such as root and shoot length and increase of dry weight (Mitra et al. 2014; Šerá et al., 2010; Jiafeng et al., 2014). Plasma treatment resulted in a change of seed surface wettability, improved hydrophilic properties of the seed surface, and led to better water imbibition and faster start of the germination process (Stolárik et al., 2015; Zahoranová et al., 2016). Plasma technology has the potential to play an important role in addressing the challenges in food production and security, as reviewed in many articles (Moreau et al., 2008; Cullen et al., 2018; Randeniya and de Groot, 2015; Muhammad et al., 2018; Zahoranová et al., 2018; Chen et al., 2019).

In this study, a hypothesis that additional application of LTP in decontamination treatment of seeds reduces the chemical load on the environment without negative changes in seed morphology and physiology has been proposed and evaluated. Plasma interaction with wheat and barley seeds was studied and plasma treatment and application of chemical fungicide Vitavax 2000 on Fusarium culmorum on the surface of wheat and barley seeds were compared. The effect of a combination of plasma and fungicide treatments was also determined.

\section{Materials and methods}

\section{Cereal seeds and microbial strains}

Wheat seeds (Triticum vulgare L.; cv. "Forhand") and barley seeds (Hordeum vulgare L.; cv. "Maltz") were purchased from the Central Control and Testing Agriculture Institute (Bratislava, Slovak Republic). The seeds were stored at $10^{\circ} \mathrm{C}$ in the dark. Fusarium culmorum (CCM F-163) was obtained from the Czech Collection of Microorganisms (Masaryk University, Brno, Czech Republic) and was cultivated on slants of Malt Extract Agar (Biolife, Milano, Italy; 21 days, $25^{\circ} \mathrm{C}$ ) and then stored at $5^{\circ} \mathrm{C}$.

\section{Low-temperature plasma reactor}

The experiments were carried out at atmospheric pressure in ambient air. Plasma was generated by Diffuse Coplanar Surface Barrier Discharge (DCSBD). The experimental set-up is depicted in Fig. 1. DCSBD was powered by $14 \mathrm{kHz}$ sinusoidal high voltage with an amplitude of up to $20 \mathrm{kV}$ peak-to-peak, supplied by an $\mathrm{HV}$ generator VF 700 (Lifetech Ltd., Brno, Czech Republic). DCSBD generates a thin layer of plasma $(\sim 0.3 \mathrm{~mm})$ on a ceramic plate with the dimensions of $20 \mathrm{~cm} \times 8 \mathrm{~cm}$. DCSBD was described in detail in previous studies (Černák et al., 2009).

Seeds/sterilzed seeds ( $10 \mathrm{~g})$ were placed in the plasma generated on the ceramic plate. To ensure their uniform surface treatment, mechanically stirring was applied. The experiments were performed at the input power of $400 \mathrm{~W}$ while the whole DCSBD electrode was covered by macroscopically homogeneous plasma layer. From the electric measurement and determination of plasma source efficiency, and the size of the plasma area $\left(160 \mathrm{~cm}^{2}\right)$, the corresponding plasma volume power density was determined to be approximately $70 \mathrm{~W} \mathrm{~cm}^{-3}$ (Černák et al., 2009).

\section{Cereal seeds surface decontamination from Fusarium culmorum}

Ten grams of wheat and barley sterile (autoclaving $\left.-120 \mathrm{kPa}, 120{ }^{\circ} \mathrm{C}, 20 \mathrm{~min}\right)$ seeds were artificially infected with $1 \mathrm{~mL}$ of spore suspension of seed-borne phytopathogen $F$. culmorum $\left(1 \times 10^{5}\right.$ spores $\left.\mathrm{g}_{\text {seed }}{ }^{-1}\right)$. The spore suspension was prepared from 21-day-old cultures grown on Malt Extract Agar medium (Biolife, Milano, Italy). The spores were harvested in $0.1 \%$ Tween 80 (Biolife, Milano,

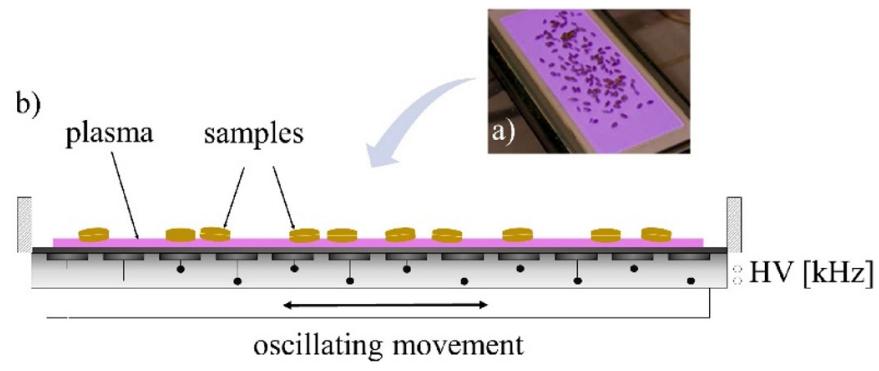

Fig. 1. LTP treatment of seeds (a) and scheme of the DCSBD electrode system (b) 
Italy). The spore suspension was filtered through three lavers of sterile gauze and centrifuged at $12000^{\times} \mathrm{g}$ for $5 \mathrm{~min}$. The number of spores was counted using a Burker chamber. Concentration of spores was adjusted by sterile water. The infected seeds were treated by LTP at the treatment time of 15, 30, 60, 120, 180, 240 and $300 \mathrm{~s}$. Chemical fungicide Vitavax 2000 (200 g a.i. thiram and carboxin $\mathrm{L}^{-1}$; Chemtura Co., Bratislava, Slovakia) was used in different doses (100\% - application dose used in agricultural practice and $75 \%, 50 \%, 25 \%, 10 \%$ of the dose used). After 15, 30 and $60 \mathrm{~s}$ of LTP treatment and subsequent application of Vitavax 2000 at a $10 \%, 25 \%$ and $50 \%$ dose were combined for seed treatment. Twenty hours later (time required to air dry the seeds treated by fungicide), individual samples of wheat and barley seeds, as well as of untreated control, were placed on the Malt Extract Agar medium (Biolife, Milano, Italy; 50 seeds per Petri dish with diameter of $185 \mathrm{~mm}$ ). After five days of incubation at $25^{\circ} \mathrm{C}$, each individual cereal seed was visually classified on a scale of $0-5$ according to the intensity of fungal attack on the surface of each cereal seed. Score equal to 0 indicated an absence of fungal attack; the score of 5 - fungal attack of more than $60 \%$ of the infected seed surface. The infection degree (ID) was calculated using the Townsend-Heuberger's formula (1) (Rekanovic et al., 2010):

$$
I D=\frac{\sum(n v) \times 100}{N V}
$$

$n$ - degree of infection rate (scale $0-5), v-$ number of seeds in each category, $N$ - highest degree of infection rate, $V$ - total number of seeds screened. Efficacy of seed surface treatment using fungicide, plasma, and plasma + fungicide combination was compared.

\section{Seed surface diagnostics}

\section{A. Water contact angle}

Wettability changes were identified by measuring the water contact angle (WCA) on the seed surface after plasma treatment using a DSA30 device (Krüss GmbH, Hamburg, Germany). The volume of water droplets was $2 \mu \mathrm{L}$ and the average value of WCA for each sample was calculated from 12 droplets recorded by a CCD camera and processed using additional software for Drop Shape Analysis DSA1 allowing analysis of a curved surface.

\section{B. Scanning electron microscopy (SEM)}

SEM measurements were performed using a Scanning Electron Microscope Vega II SBH (Tescan, Czech Republic) at the acceleration voltage of
$30 \mathrm{kV}$ and magnification of $150 \times$. The samples were plated with gold by SEM Coating System (BIORAD E52-5199) at the pressure of $8 \mathrm{~Pa}$ in argon. Thickness of the gold layer was $20 \mathrm{~nm}$.

\section{Seed germination}

Cereal seeds were treated by LTP for 15-300 s. Fifty pieces of LTP treated and untreated wheat and barley seeds were placed on a continuously wetted filter paper (Whatman 1) in sterile Petri dishes (diameter of $185 \mathrm{~mm}$ ) and incubated for five days at $25^{\circ} \mathrm{C}$. Germination $(\mathrm{G})$ was calculated by the following equation (2):

$$
G=\frac{S G}{S T} \times 100 \%
$$

where $G$ - germination, $S G$ - number of germinated seeds, $S T$ - total number of seeds.

Vigor of the seedlings was evaluated by measuring the root length and shoot length of the seedlings. Seedling vigor index was calculated according to Eq. (3) (Abdul-Baki and Anderson, 1973):

$$
S V=\frac{(L R+L S) \times G(\text { treated seeds })}{(L R+L S) \times G(\text { untreated seeds })} \times 100 \%
$$

where $S V$ - seedling vigor, $L R$ - length of roots in $\mathrm{mm}, L S$ - length of shoots in $\mathrm{mm}, G$ - germination.

\section{Statistical analysis}

Significant differences between the samples were determined using the one-way analysis of variance (ANOVA) with post hoc tests with the Bonferroni correction. Differences were considered significant for $* P<0.05 ; * * P<0.01$; *** $P<0.001$. Values are expressed as the mean \pm standard deviation $(\mathrm{SD})$ of at least five measurements.

\section{Results}

\section{Cereal seed surface decontamination from Fusarium culmorum}

Two methods were used to reduce the growth of $F$. culmorum on the surface of cereal seeds: a chemical method using the fungicidal effect of Vitavax 2000 and a physical method using the effect of LTP. For the chemical treatment of cereal seeds, Vitavax 2000 was used in doses from $10 \%$ to $100 \%$ of standard recommended agricultural application. In Fig. 2, significantly different results of the fungicide protective effect were obtained for wheat and barley seeds. In wheat, a significant decrease in the ID to $60 \%$ was observed after using a $10 \%$ dose of the fungicide. With the increase of the fungicide dose, the ID dropped significantly. However, even after applying a $100 \%$ fungicide dose, complete elimination of $F$. culmorum on the surface of wheat 


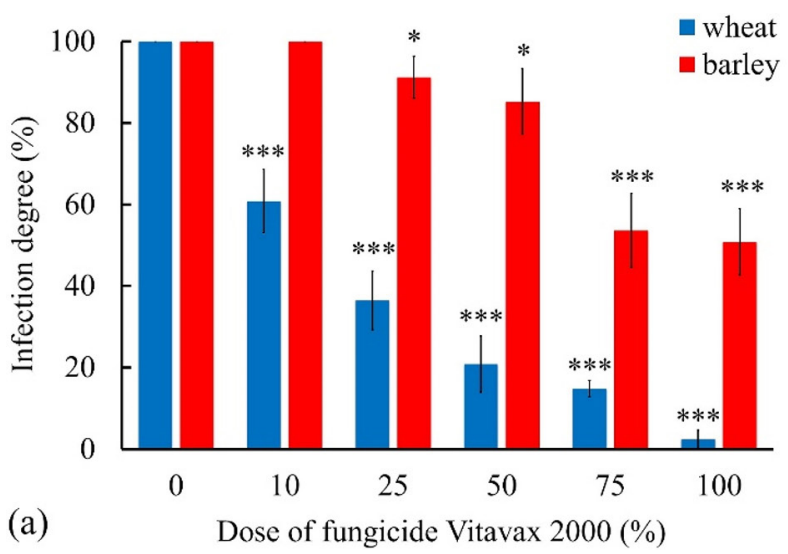

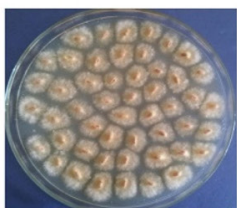

(b) untreated

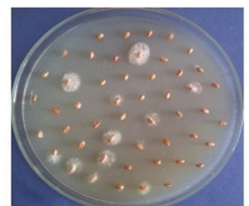

(c) fungicide treated $(50 \%)$

Fig. 2. Decontamination of cereal seed surface from seed-borne phytopathogen F. culmorum after Vitavax 2000 application (a). Results were significant at $* P<0.05$; $* * * P<0.001$ compared to control ( $0 \%$ dose of Vitavax 2000). Growth of F. culmorum on the surface of untreated wheat seeds (b) and after the application of a $50 \%$ dose of Vitavax 2000 (c).

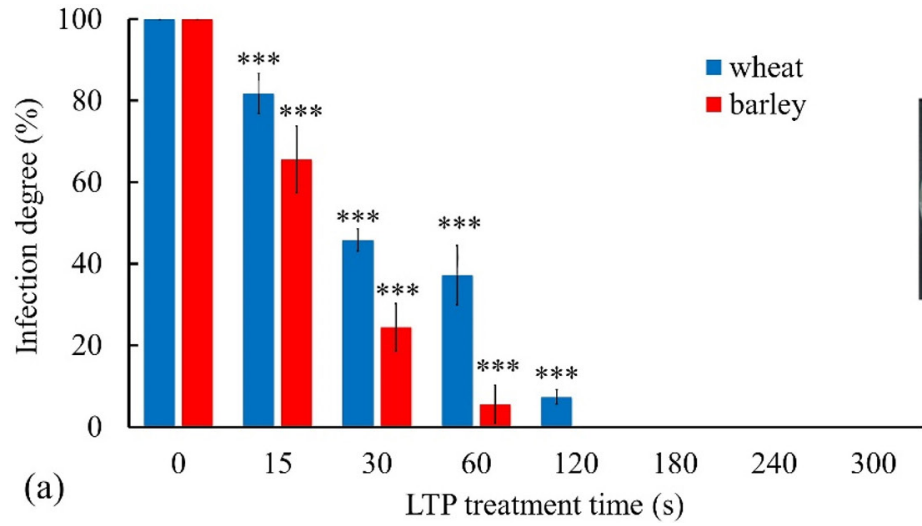

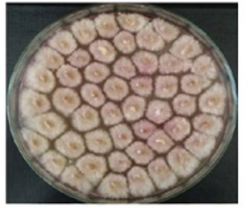

(b) untreated

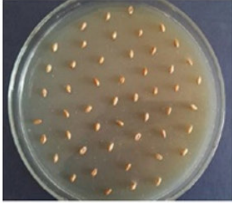

(c) plasma treated $(180 \mathrm{~s})$

Fig. 3. Decontamination of cereal seed surface from seed-borne phytopathogen F. culmorum after plasma treatment (a). Results were significant at $* * * P<0.001$ compared to control $(0 \mathrm{~s}$ LTP). Growth of F. culmorum on the surface of untreated wheat seeds (b) and after the application of $180 \mathrm{~s}$ of LTP treatment (c).

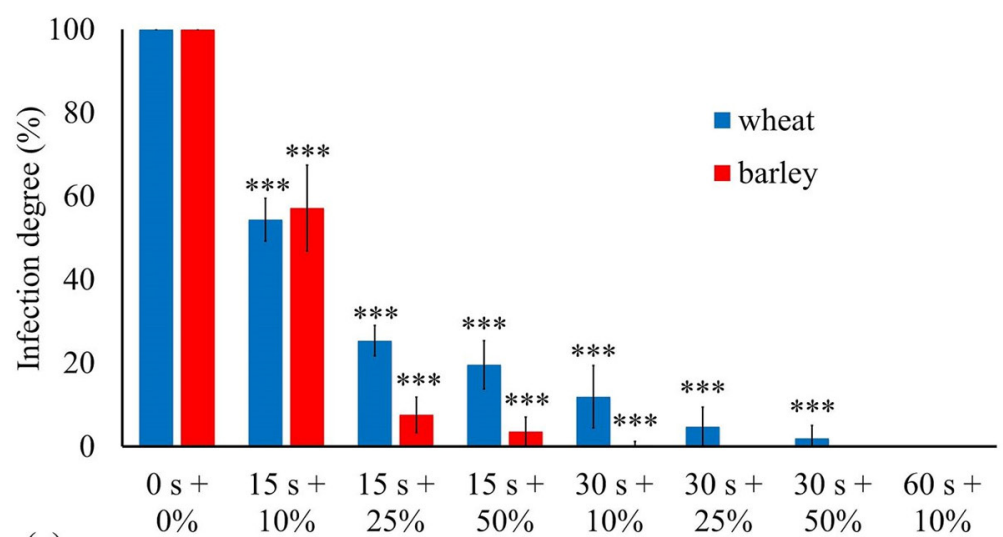

(a)

LTP treatment time (s) and dose of fungicide Vitavax $2000(\%)$

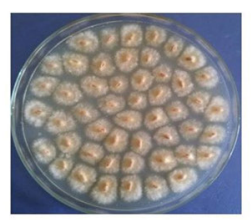

(b) untreated

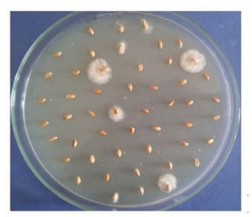

(d) $30 \mathrm{~s} \mathrm{LTP}+$ $10 \%$ fungicide

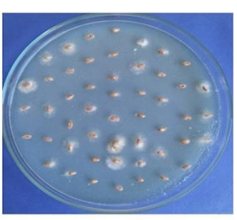

(c) $0 \mathrm{~s} \mathrm{LTP}+$ $10 \%$ fungicide

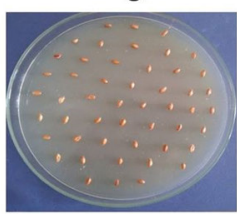

(e) $60 \mathrm{~s} \mathrm{LTP}+$ $10 \%$ fungicide

Fig. 4. Decontamination of cereal seed surface from seed born phytopathogen F. culmorum after combined treatment (LTP + fungicide) (a). Results were significant at ${ }^{* * *} P<0.001$ compared to control ( $0 \mathrm{~s} \mathrm{LTP}+0 \%$ fungicide). Growth of F. culmorum on the surface of untreated wheat seeds (b) and after the application of combined treatment $(0 s+10 \%$ (c); $30 s+10 \%$ (d); $60 s+10 \%$ (e)). 
seeds was not reached - ID was below $5 \%$. A $10 \%$ dose of fungicide on barley seeds had no effect on the ID. The reduction of ID after the application of a $50 \%$ fungicide dose was only about $20 \%$ and a $100 \%$ dose led to a $50 \%$ reduction in F. culmorum on the barley seed surface.

In physical treatment, the seeds were exposed to LTP for 15-300 s (Fig. 3). After $15 \mathrm{~s}$ of LTP treatment, a significant decrease of $20 \%$ in wheat seed ID was observed and of more than $30 \%$ in barley seeds. After $30 \mathrm{~s}$ of plasma treatment, ID of the seeds was below $50 \%$ for both kinds of cereals. Complete devitalization of $F$. culmorum on the wheat seed surface was observed after $180 \mathrm{~s}$ of plasma exposure and after $120 \mathrm{~s}$ in barley seeds.

The effect of the combined treatment (LTP + Vitavax 2000) on the reduction of F. culmorum is presented in Fig. 4. A significant decrease of the ID in both cereal seeds to about $60 \%$ was achieved after $15 \mathrm{~s}$ of LTP combined with a $10 \%$ fungicide dose. With the increasing LTP exposure time and fungicide dose, the cereal seeds infection degree decreased significantly. Complete reduction of $F$. culmorum on the surface of cereal seeds was observed after the combined treatment applying $60 \mathrm{~s}$ LTP $+10 \%$ dose of fungicide.

\section{Seed surface diagnostics - WCA and SEM}

LTP treatment caused changes in the surface properties of cereal seeds. Wettability of wheat and barley seed surface was determined by measuring the WCA of a distilled water drop. WCA of the cereal seed reference samples was $106.4^{\circ} \pm 9.4^{\circ}$ (wheat) and $95.2^{\circ} \pm 2.4^{\circ}$ (barley). The surface of a sample with WCA above $90^{\circ}$ is considered as hydrophobic. After a $10 \mathrm{~s}$ exposure of seeds to LTP, a decrease of WCA to $56.9^{\circ} \pm 8.6^{\circ}$ for wheat and to $61.8^{\circ} \pm 5.21^{\circ}$ for barley was observed and the samples became hydrophilic; contact angles of the cereal seeds were less than $5^{\circ}-$ maximum
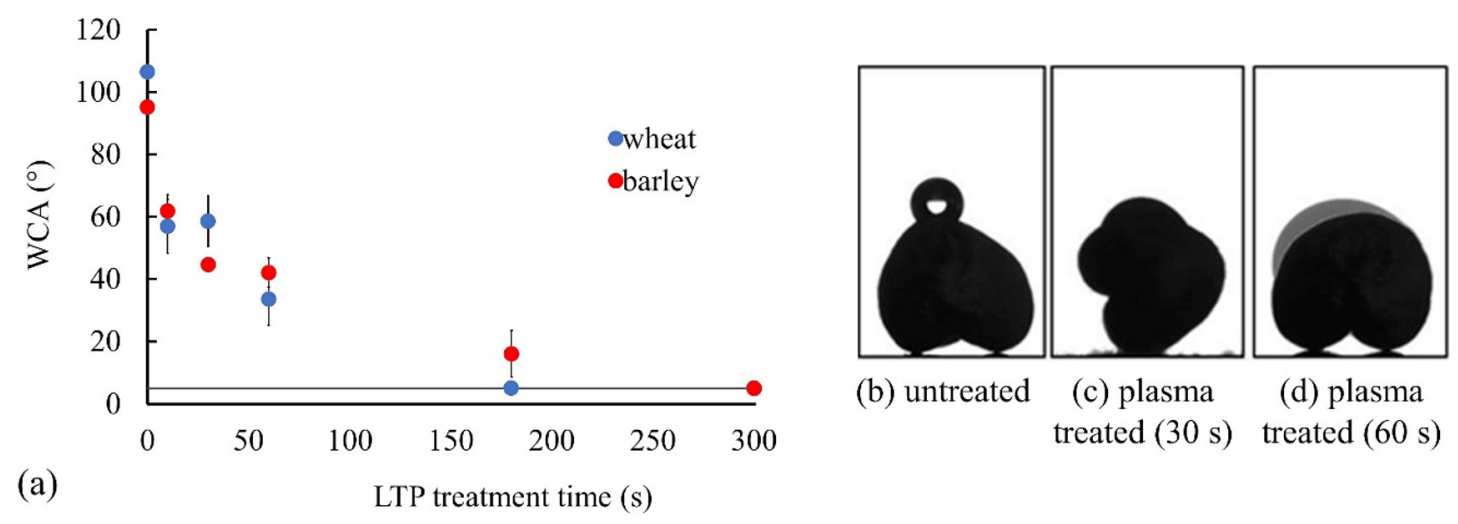

Fig. 5. Effect of treatment time on the water contact angle measured on cereal seed samples treated by LTP (a). A drop of water on the surface of untreated (b) and LTP treated barley seeds (c, d).

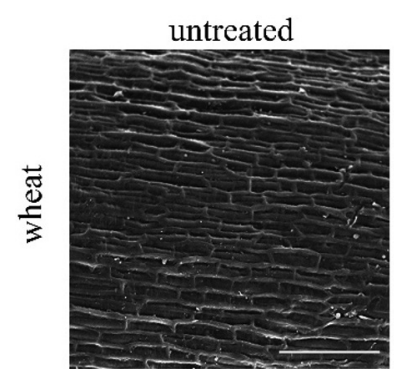

untreated

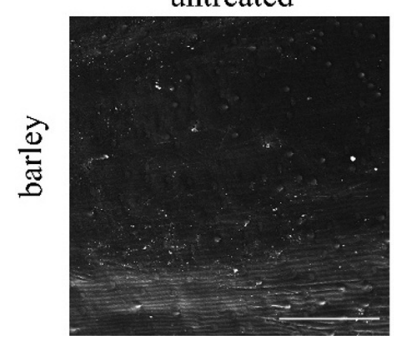

plasma treated

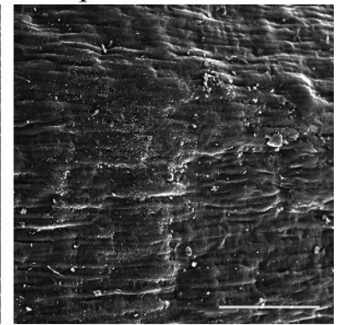

plasma treated

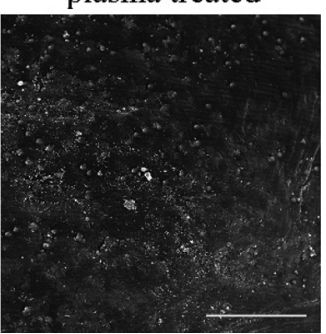

Fig. 6. Scanning electron microscopy (SEM) of untreated and plasma treated (120 s) wheat and barley seeds. Total magnification was 150×; SEM HV 30 kV; scale bars represent $200 \mu \mathrm{m}$. 
Tab. 1. Germination (G) and seedling vigor (SV) of cereal seeds after LTP treatment compared to untreated control.

\begin{tabular}{lcccc}
\hline \multirow{2}{*}{ LTP treatment $(\mathbf{s})$} & \multicolumn{2}{c}{ wheat } & \multicolumn{2}{c}{ barley } \\
\cline { 2 - 5 } & $\mathbf{G}(\%)$ & $\mathbf{S V}(\%)$ & $\mathbf{G}(\%)$ & SV $(\%)$ \\
\hline $\mathbf{0}$ & $100 \pm 0$ & $100 \pm 0$ & $100 \pm 0$ & $100 \pm 0$ \\
$\mathbf{1 5}$ & $100 \pm 0$ & $117 \pm 4^{* *}$ & $100 \pm 0$ & $115 \pm 7^{* *}$ \\
$\mathbf{3 0}$ & $98 \pm 4$ & $99 \pm 13$ & $98 \pm 4$ & $101 \pm 5$ \\
$\mathbf{6 0}$ & $96 \pm 8$ & $74 \pm 18$ & $94 \pm 8$ & $74 \pm 10^{* *}$ \\
$\mathbf{1 2 0}$ & $80 \pm 10^{*}$ & $23 \pm 12^{* * *}$ & $72 \pm 15^{*}$ & $20 \pm 5^{* * *}$ \\
$\mathbf{1 8 0}$ & $74 \pm 10^{* *}$ & $14 \pm 5^{* * *}$ & $54 \pm 14^{* * *}$ & $10 \pm 3^{* * *}$ \\
$\mathbf{2 4 0}$ & $52 \pm 11^{* * *}$ & $4 \pm 5^{* * *}$ & $48 \pm 4^{* * *}$ & $4 \pm 0.8^{* * *}$ \\
$\mathbf{3 0 0}$ & $46 \pm 10^{* * *}$ & $3 \pm 3^{* * *}$ & $32 \pm 7^{* * *}$ & $2 \pm 0.6^{* * *}$ \\
\hline
\end{tabular}

Results were significant at $* P<0.05 ; * * P<0.01 ; * * * P<0.001$ compared to control.

hydrophilic surface $\left(\right.$ WCA $\left.<5^{\circ}\right)$, after a $180 \mathrm{~s}$ LTP treatment of wheat seeds and after a $300 \mathrm{~s}$ LTP treatment of barley seeds (Fig. 5).

Seed surface morphology before and after the plasma treatment was compared by SEM. As it can be seen in Fig. 6, not even a 120 s plasma treatment caused significant changes in the cereal seed surface. In case of wheat seeds, slight surface smoothing was observed while no visible surface changes were observed in barley seeds.

\section{Seed germination and seedling vigor}

The effect of plasma treatment on germination and seedling vigor of cereal seeds is summarized in Tab. 1. Cereal germination was not adversely affected after a $15 \mathrm{~s}$ plasma exposure. On the contrary, slight stimulation of growth parameters (seedling vigor) in both cereals was achieved. The $30 \mathrm{~s}$ and $60 \mathrm{~s}$ plasma treatment resulted in a minor decrease of germination. A $60 \mathrm{~s}$ treatment by LTP inhibited the growth parameters of wheat and barley seeds by almost $30 \%$. Effect of a 120 s plasma treatment caused inhibition of the seed growth parameters by almost $80 \%$. After $300 \mathrm{~s}$ of treatment, the germination of both cereal seeds decreased below $50 \%$ and the seedling vigor was less than $5 \%$. Seeds with germination below $80 \%$ are not suitable for planting.

\section{Discussion}

Vitavax 2000 is a combined fungicide which acts as a systemic and contact fungicide inhibiting spore germination and blocks the growth of some fungal pathogens. Vitavax 2000 in various doses was used to decontaminate wheat and barley seeds' surface from F. culmorum. While almost complete devitalization of $F$. culmorum was achieved with a $100 \%$ fungicide dose used in agriculture for presowing seed treatment of wheat, in case of barley it was only about $50 \%$ (Fig. 2). This difference is probably due to the morphological difference (size and surface) between wheat and barley seeds. Fungicides are designed to protect emerging plants (wheat, barley, maize). A positive effect of fungicides on germination and root growth has also been observed in chickpea, maize, peanuts (Dhanamanjuri et al., 2013; El-Deeb et al., 2002). The effect of fungicides on the quality of lentil seeds during storage was also investigated previously (Khatun et al., 2016). Fungicide treated seeds demonstrate higher germination and seedling vigor than untreated seeds. However, the yield of seeds is not affected only by fungicides but also by other factors (temperature, drought) (Jalakas et al., 2018; Stetkiewicz et al., 2019). The efficacy of some long-term used fungicides has been influenced by the development of antifungal resistance in target fungal pathogens (Ishii and Holloman, 2015; Lucas et al., 2015). Although the use of fungicides in agriculture cannot be completely excluded, ways to reduce their levels are researched, which could ultimately slow down the spread and development of resistance to fungicides and reduce the chemical burden of the environment.

LTP was used as a possible alternative method to chemical seed protection. A significant decrease of fungal contamination after $15 \mathrm{~s}$ of plasma treatment was observed. Complete decontamination of the seed surface of both cereals was achieved after a 180 s LTP exposure (Fig. 3). The effect of plasma was also investigated on maize seeds (Zahoranová et al., 2018). F. culmorum was completely devitalized after $120 \mathrm{~s}$. This result is comparable with the results presented in this study.

Improvement of seed germination is also caused by the decontamination of the seed surface (Yvin and Coste, 1997; Guang-Liang et al., 2005; Dobrin et al., 2015), which could be significant because phytopathogenic microorganisms negatively influence the 
seed quality and subsequent production of any agriculture commodity. In comparison, physical treatment does not protect the seeds after their placement in soil. In this study, physical plasma treatment and chemical fungicide application were combined in synergistic treatments to protect seeds from fungal contamination. The results showed a beneficial effect of LTP on F. culmorum decontamination as well as the reduction of fungicide doses needed. A significant decrease of cereal seed contamination was already observed after combined treatment applying 15 s LTP and $10 \%$ Vitavax 2000. Combination of 60 s of plasma and $10 \%$ Vitavax 2000 was sufficient for complete $F$. culmorum decontamination, which represents a $90 \%$ reduction in the fungicide dose (Fig. 4). The combination of LTP + Vitavax 2000 seems to be the most appropriate method.

LTP also changes the surface properties of the seeds. The surface of wheat and barley seeds changed from hydrophobic to hydrophilic after $10 \mathrm{~s}$ of plasma treatment (Fig. 5). Prolongation of the LTP exposure led to a drop in the contact angle of distilled water below $5^{\circ}$, making the seed surface perfectly hydrophilic as opposed to the hydrophobic surface of untreated seeds. LTP can modify the seed surface and thus increase its wettability and absorbability. This feature is of interest in agriculture because better water absorption reduces the seed requirements for water content in the environment during the germination period. Plasma treated seeds are more wettable which improves the adhesion of the fungicide to their surface and thus, a smaller dose of fungicide is required to cover the seed surface in comparison to untreated seeds. SEM confirmed that plasma does not cause visible morphological changes in the surface of barley seeds and only very slight morphological changes in the surface of wheat seeds (Fig. 6). Stolárik et al. (2015) detected significant surface structural modifications in pea seeds after $120 \mathrm{~s}$ of plasma treatment using electron microscopy. Disruptions, abrasions and loosening of the original structures were observed. Such significant changes were not observed in maize, which is probably due to different seed hardness (Zahoranová et al., 2018). Based on the results obtained from WCA and SEM, the surface changes of the seeds after plasma application were caused by a change in the chemical structure of seed surface and not by morphological changes.

In this study, the effect of plasma on seed germination was investigated. To improve seed absorption, plasma treatment is expected to have positive effect on germination. This would correlate with the published results (Bafoil et al., 2018; Štěpánová et al., 2018; Magureanu et al., 2018; Guo et al., 2018;
Los et al., 2018). A 15 s plasma treatment did not affect germination but stimulated the growth parameter of the seeds of both cereals. After $30 \mathrm{~s}$ and $60 \mathrm{~s}$ of plasma application, germination inhibition was minor. A $60 \mathrm{~s}$ plasma treatment caused a $26 \%$ inhibition of growth parameters (Tab. 1). It was concluded that a $60 \mathrm{~s}$ LTP treatment is the most potent in combined seed treatment reducing the fungicide dose. Vitavax 2000 fungicide itself had positive effect on growth parameters (unpublished results), which could compensate for the inhibition of growth parameters caused by plasma. Positive effects of plasma (shorter exposure times) on growth parameters have also been found in maize, wheat, soybeans, peas (Zahoranová et al., 2016; Henselová et al., 2012; Roy et al., 2018; Pizá et al., 2018). LTP treatment of the seeds for more than $60 \mathrm{~s}$ resulted in germination and growth parameters inhibition.

\section{Conclusion}

Experimental results presented in this study indicate that low-temperature atmospheric pressure plasma generated by a plasma source based on DCSBD in ambient air can be successfully used for the treatment of cereal seeds. LTP treatment of wheat and barley seeds led to increased surface wettability and therefore better germination and chemical fungicide penetration. The synergistic effect of fungicide and LTP treatment used against seed-borne phytopathogens present on the surface of wheat and barley seeds was more effective than when each of them is used individually. An optimal combination of plasma treatment time and chemical fungicide dose can significantly reduce the use of harmful chemicals in practice but at the same time stimulate germination via plasma treatment. Our data demonstrate that $30 \mathrm{~s}$ of LTP treatment is the optimal dose to reduce of F. culmorum by more than $80 \%$ and the amount of fungicides by 50-90\% without impairment of seed physiology. Furthermore, the combinatory approach to seed treatment can also be used for other phytopathogenic fungi, but optimization is required. The data presented in this study provide a good basis for further experiments that have to be performed directly in soil.

\author{
Acknowledgement \\ This study was supported by the Slovak Research and \\ Development Agency under the contract No. APVV-16- \\ 0216.
}

\section{Declarations of interest}

None. 


\section{References}

Abdul-Baki AA, Anderson JD (1973) Crop Science 13: 630-633.

Bafoil M, Jemmat A, Martinez Y, Merbahi N, Eichwald O, Dunand C, Yousfi, M (2018) PLOS One 13: 1-16.

Černák M, Černáková L, Hudec I, Kováčik D, Zahoranová A (2009) The European Physical Journal Applied Physics 47.

Chen D, Peng P, Zhou N, Cheng Y, Min M, Ma Y, Mao Q, Chen P, Chen C, Ruan R (2019) Food chemistry 290: 270-276.

Cullen PJ, Lalor J, Scally L, Boehm D, Milosavljević V, Bourke P, Keener K (2018) Plasma Processes and Polymers 15: 1-11.

Dhanamanjuri W, Thoudam R, Dutta BK (2013) MiddleEast Journal of Scientific Research 17: 627-632.

Dobrin D, Magureanu M, Mandache NB, Ionita MD (2015) Innovative Food Science and Emerging Technologies 29: 255-260.

El-Deeb AA, Abdel-Momen SM, Hanafi AA (2002) Egyptian Journal of Agricultural Research 80: 71-82.

Guang-Liang C, Song-Hua F, Chun-Ling L, Wei-Chao G, Wen-Ran F, Gu-Ling Z, Jiu-Li W, Latif K, Shu-Gen Z, Zhen-Quan W, Er-Li H, Ya-Bo F, Si-Ze Y (2005) Chinese Physics Letters 22: 1980.

Guo Q, Meng Y, Qu G, Wang T, Yang F, Liang D, Hu S (2018) Bioelectromagnetics 39: 120-131.

Henselová M, Slováková L, Martinka M, Zahoranová A (2012) Biologia 67: 490-497.

Ishii H, Holloman DW (2015) Fungicide resistance in plant pathogens. Springer, Tokyo.

Jalakas P, Tulva I, Kangor T, Sooväli P, Rasulov B, Tamm Ü, Koppel M, Kollist H, Merilo E (2018) European Journal of Agronomy 99: 129-137.

Jiafeng J, Xin H, Ling LI, Jiangang L, Hanliang S, Qilai X, Renhong Y, Yuanhua D (2014) Plasma Science and Technolog. 16: 54.

Khatun A, Bhuiyan MAH, Tahmid A (2016) Jahangirnagar University Journal of Biological Sciences 5: 51-56.

Laca A, Mousia Z, Díaz M, Webb C, Pandiella SS (2006) Journal of Food Engineering 72: 332-338.

Los A, Ziuzina D, Akkermans S, Boehm D, Cullen PJ, Van Impe J, Bourke P (2018) Food Research International 106: 509-521.

Lucas JA, Hawkins NJ, Fraaije BA (2015) Advances in Applied Microbiology 90: 29-92.

Magan N, Hope R, Cairns V, Aldred D (2003) In: Xu X., Bailey JA, Cooke BM (Eds.), Epidemiology of Mycotoxin Producing Fungi. Springer, Dordrecht, pp. 723-730.

Magureanu M, Sîrbu R, Dobrin D, Gîdea M (2018) Plasma Chemistry and Plasma Processing 38: 989-1001.

McMullen M, Bergstrom G, DeWolf E, Dill-Macky R, Hershman D, Shaner G, Sanford DV (2012) Plant Disease 96: 1712-1728.
Mitra A, Li YF, Klämpfl TG, Shimizu T, Jeon J, Morfill GE, Zimmermann JL (2014) Food and Bioprocess Technology 7: 645-653.

Montville TJ, Matthews KR (2005) Food microbiology. ASM Press, Washington.

Moreau M, Orange N, Feuilloley MGJ (2008) Biotechnology Advances 26: 610-617.

Muhammad AI, Liao X, Cullen PJ, Liu D, Xiang Q, Wang J, Chen S, Ye X (2018) Comprehensive Reviews in Food Science and Food Safety 17: 1379-1394.

Pereira VL, Fernandes JO, Cunha SC (2014) Trends in Food Science \& Technology 36: 96-136.

Pizá MCP, Prevosto L, Zilli C, Cejas E, Kelly H, Balestrasse $\mathrm{K}$ (2018) Innovative Food Science and Emerging Technologies 49: 82-91.

Ramos AJ, Labernia N, Marín S, Sanchis V, Magan N (1998) International Journal of Food Microbiology 44:133-140.

Randeniya LK, de Groot GJJB (2015) Plasma Processes and Polymers 12: 608-623.

Rekanovic E, Potocnik I, Milijasevic-Marcic S, Stepanovic M, Todorovic B, Mihajlovic M (2010) Pesticides and phytomedicine 25: 319-324.

Roy NC, Hasan MM, Talukder MR, Hossain MD, Chowdhury AN (2018) Plasma Chemistry and Plasma Processing 38: 13.

Šerá B, Špatenka P, Šerý M, Vrchotová N, Hrušková I (2010) IEEE Transactions on Plasma Science 38: 2963-2968.

Šimončicová J, Kryštofová S, Medvecká V, Durišová K, Kaliňáková B (2019) Applied Microbiology and Biotechnology 103: 5117-5129.

Štěpánová V, Slavíček P, Kelar J, Prášil J, Smékal M, Stupavská M, Jurmanová J, Černák M (2018) Plasma Processes and Polymers 15: 1-9.

Stetkiewicz S, Burnett FJ, Ennos RA, Topp CF (2019) European Journal of Agronomy 105: 111-118.

Stolárik T, Henselová M, Martinka M, Novák O, Zahoranová A, Černák M (2015) Plasma Chemistry and Plasma Processing 35: 659-676.

Tančínová D, Kačániová M, Javorekova S (2001) Biologia 56: $247-250$.

United Nations, Food and Agriculture Organization, Statistics Division (FAOSTAT) (2019) http://www.fao. org/faostat/en/\#data/QG (accessed 7 October 2019).

Yvin JC, Coste C (1997) U.S. Patent No. 5,703,009. Washington, DC: U.S. Patent and Trademark Office.

Zahoranová A, Henselová M, Hudecová D, Kaliňáková B, Kováčik D, Medvecká V, Černák M (2016) Plasma Chemistry and Plasma Processing 36: 397-414.

Zahoranová A, Hoppanová L, Šimončicová J, Tučeková Z, Medvecká V, Hudecová D, Kaliňáková B, Kováčik D, Černák M (2018) Plasma Chemistry and Plasma Processing 38: 969-988. 